\title{
Learning Styles of Students and Professors of a Dental School in Latin America: A Cross-Sectional Study
}

\author{
Carlos M. Ardila ${ }^{1,2}$, Angela-María Goméz-Restrepo ${ }^{1}$ \& Cruzana Echeverri-Restrepo ${ }^{1}$ \\ ${ }^{1}$ School of Dentistry Universidad de Antioquia, Medellín, Colombia \\ ${ }^{2}$ Biomedical Stomatology Research Group Universidad de Antioquia, Medellín, Colombia \\ Correspondence: Carlos M. Ardila, School of Dentistry Universidad de Antioquia, Medellín, Colombia. Calle 70 \\ No.52-21, Medellín, Colombia. Tel: 57-4-219-6700. E-mail: martin.ardila@udea.edu.co
}

Received: October 18, 2019 Accepted: November 13, 2019 Online Published: November 20, 2019

doi:10.5539/gjhs.v11n13p104

URL: https://doi.org/10.5539/gjhs.v11n13p104

\begin{abstract}
Purpose: To recognize the learning styles of applicants, dental students, and professors with several academic degrees. Besides, it was explored the association between grade point average (GPA) of the students and their learning styles.

Methods: It was designed a cross-sectional research. The present research was attended by applicants admitted for a place in the academic period 2019-1 and by the students of the Faculty of Dentistry enrolled during the academic period 2018-2. Besides, all professors were invited to participate. The participants responded to a validated questionnaire to identify their learning style after signing the informed consent. The T-student test was executed to calculate the differences between the groups; besides, post-hoc check was run. Linear regression models were performed expressed in $\beta$ and $95 \%$ confidence intervals. P values of $<0.05$ were contemplated as statistically significant.
\end{abstract}

Results: A total of 34 applicants, 425 students, and 121 professors participated in the present research. Students and professors presented preference for the theorist and reflector styles; however, the applicant students had a higher preference for the theorist $(\mathrm{p}=.002)$, and pragmatist styles $(\mathrm{p}<.001)$. A significant correlation was observed between the higher GPA of the students and the theorist style $(\mathrm{r}=.2 ; \mathrm{p}<.0001)$. The multivariate linear regression model showed that the theorist style protects against a lower mean of GPA in students $(\beta=-.2 ; \mathrm{p}=.018)$ after adjusting for sex, age, public high school, and semester enrolled. Besides, professors favored the theorist and reflector styles.

Conclusions: Students and professors preferred the theorist and reflector styles; however, the applicant students favored the theorist and pragmatist. Besides, the theorist style protected against a lower mean of GPA in students.

Keywords: dental faculty, dental students, education, educational achievement, learning, faculty.

\section{Introduction}

A variety of authors theorized the learning styles (LS); they defined diverse models and instruments attempting the election of the most suitable (Coffield et al., 2004; Alonso et al., 2012). Alonso et al. (2012) adopted one of the most recognized (Keefe, 1988). They supported that LS are the "cognitive, affective, and physiological" attributes that assist as indicators moderately constant as students distinguish, interrelate, and respond to their learning contexts. The undergraduates construct their learning method, following on a repetitive movement from practice. A total of four LS are recognized ("activist, reflector, theorist and pragmatist") (Table 1) from the Learning Styles Questionnaire (LSQ) proposed previously (Honey \& Mumford, 1986), based on the inventory of LS of Kolb (1984), defining four LS as well (accommodating, assimilating, divergent and convergent). The LSQ was designed for business reasons and changed into a Spanish academic environment (called CHAEA) (Alonso et al., 2012). 
Table 1. Features of the learning styles (Honey \& Mumford, 1986)

\begin{tabular}{ll}
\hline Learning Style & Features \\
\hline Activist & Enthusiast, Improvise, Spontaneous \\
Reflector & Prudent, Receptive, Analytical \\
Theorist & Methodical, critical, organized \\
Pragmatist & Experimenter, direct, realistic \\
\hline
\end{tabular}

The CHAEA (Alonso et al., 2012) questionnaire has been applied to health sciences learners to recognize their LS (Czepula Bottacin et al., 2016; Márquez et al., 2014; González-Haro et al., 2010). It was lately revised given difficulties detected through its realization (prolonged reply intervals, misunderstood questions, and binary replies); therefore, the understanding of the form was enhanced using a more direct semantic; the interpretation of the LS was correspondingly conserved, and superior feedback choices were provided. The new version, termed CAMEA40 (Madrigal \& Trujillo, 2014) was validated with university students, and it was adapted into the Italian language (Pulcini et al., 2018).

Considering its modern edition from the Honey-Alonso form of LS (1986) and pondering that LS and measures implemented are comparable to those of the CAMEA40, it is feasible to contrast it with other studies. However, LS in dental programs have been explored scarcely in Latin America.

The relations among apprentices and professors, the curriculum, the practical-theoretic coherence, the university context, the scholarly climate, and the culture, become complex the teaching-learning process in dental schools. (Chuenjitwongsa et al., 2018). The comprehension of LS benefits teachers to monitor student knowledge. Besides, it is commended that the professors distinguish their manner of learning since it can determine the practice of teaching. It has also been accepted that persons with comparable LS exchange information in an improved type (Revilla, 1995; Coloma, 2008; Baker \& Marks, 1981). Besides, there is a reasonable agreement that dental education is recognized as demanding, tense, and fatiguing for students and professors (Divaris et al., 2012 Rutter et al., 2012).

The habituation of people with their LS can reinforce their strengths in learning and consider the need to improve their less traditional styles (Keefe, 1998). Equally, when professors know the applicants' and students' preferences in LS, it is more viable to find methodologies that allow them to learn more skillfully (Czepula et al., 2016). Moreover, it was documented that numerous features influence academic success, LS between them (Contessa et al., 2005; Richard et al., 2014).

In this context, it is necessary to know the learning styles of applicants, students, and professors to facilitate the teaching-learning process and make it efficient.

On the other hand, there are little data regarding the effect of learning styles of professors with advanced degrees on the careers of dental students. Besides, there is little information about the learning styles of applicants to dental schools. A report that stablished the features of potential dental students presented that the identification of a student LS facilitates understanding of specific needs and preferences in dental education (Morris, 2000).

Lamentably, there is insufficient information concerning the correlation that can occur among the LS of faculty members in dental schools, and much less is known about this relationship in Latin American universities. Thus, the present study aimed to recognize the LS of dental students and professors with several academic degrees, in an accredited Faculty of Dentistry. Besides, it was explored the association between grade point average (GPA) of the students and their learning styles.

\section{Method}

The Bioethics Committee (IRB03-03-19) of the Faculty of Dentistry of the University of Antioquia accepted this cross-sectional study design. The present research was managed regarding the World Medical Association Declaration of Helsinki. The participants signed the informed consent freely, approving the involvement in the present research. The questionnaires were completed in the classroom. The purposes of the research and how to complete the form were explained.

\subsection{Participants}

Applicants admitted for a place on the academic period 2019-1 attended the present investigation; also, students of the Faculty of Dentistry enrolled during the academic period 2018-2, were included. Besides, all professors were 
invited to participate.

The selection criteria comprised: students listed in one of the ten semesters of the program (period 2018-2), applicants admitted to study in the academic period 2019-1, and professors of the Faculty of Dentistry. Thus, 580 faculty members completed the CAMEA40 (Madrigal \& Trujillo, 2014) questionnaire.

The first part of the form requests aspects linked to the socio-academic data. The subsequent part includes forty brief questions with five potential responses: "always, almost always, many times, sometimes and never" (assigning a rate of 5, 4, 3,2 and 1, respectively); subsequently, the outcome is the calculation of all the answers, dispensed in four columns, equivalent to each LS.

The form is arbitrarily systematized; thus, ten queries match each LS ("activist, reflector, theorist, and pragmatist"). To deduce LS, it was recommended a hierarchy to classify the data in five inclinations: "very high, high, moderate, low, and very low" (Alonso et al., 2012); for instance, high reflector, moderate theorist. Besides, the features of the questionnaire permit that the participant selects various LS.

\subsection{Statistical Analysis}

Initially, a descriptive exploration was lead. The Kolmogorov-Smirnov test was implemented to determine data distribution. Then, a bivariate analysis was applied to operating CHI-Square and Pearson correlation. T-student test (ANOVA) was executed to calculate the differences between the groups; besides, post-hoc check was run. P values of $<0.05$ were statistically significant. Considering the statistically significant results obtained by the bivariate analysis, a linear regression was performed expressed in $\beta$ accompanied by their respective confidence intervals of 95\%. Statistical software (SPSS version 24.0, Chicago, IL) was used.

\section{Results}

Table 2 depicts the socio-academic features of the 580 faculty members (response rate $=83 \%$ ). The number of females was higher in all groups. Besides, a considerable percentage of undergraduates and applicants studied at a public high school, and they had a job. A statistically significant correlation was observed between students who have studied in public high school and lower GPA $(r=0.2 ; \mathrm{p}=0.01)$.

Table 2. Socio-academic features in 580 faculty members.

\begin{tabular}{|c|c|c|c|c|}
\hline Parameter & Applicants $(n=34)$ & Students $(n=425)$ & Professors $(n=121)$ & $P$-value \\
\hline Age (years) & $20 \pm 5^{\mathrm{a}}$ & $22 \pm 3.4^{\mathrm{a}}$ & $48 \pm 10^{\mathrm{a}}$ & $<0.001^{\mathrm{c}}$ \\
\hline Sex & & & & $\mathrm{NS}^{\mathrm{d}}$ \\
\hline Female & $24(71 \%)^{b}$ & $299(70 \%)^{b}$ & $62(51 \%)^{b}$ & \\
\hline Male & $10(29 \%)^{b}$ & $126(30 \%)^{b}$ & $59(49 \%)^{b}$ & \\
\hline $\mathrm{GPA}^{\mathrm{e}}$ & ------------ & $3.88 \pm 0.3^{\mathrm{b}}$ & -------------- & --------- \\
\hline Current semester & & & & $\mathrm{NS}^{\mathrm{d}}$ \\
\hline \multicolumn{5}{|l|}{$1-5$} \\
\hline \multirow[t]{2}{*}{$6-10$} & ----------- & $229(54 \%)^{b}$ & --------------- & \\
\hline & ----------- & $196(46 \%)^{b}$ & ----------------- & \\
\hline Public high school & $20(59 \%)^{b}$ & $291(68 \%)^{b}$ & -------------- & $N S^{d}$ \\
\hline \multicolumn{5}{|l|}{ Job (yes) } \\
\hline & $13(38 \%)^{b}$ & $122(29 \%)^{b}$ & $105(87 \%)^{b}$ & $<0.0001^{\mathrm{c}}$ \\
\hline
\end{tabular}

a) Values are presented as a mean \pm standard deviation;

b) Values are presented as number and percentage;

c) Statistically significant differences between professors and applicants and between professors and students.

d) $\mathrm{NS}=$ not statistically significant;

e) GPA=grade point average.

Interestingly, a statistically significant positive correlation was observed between the higher GPA of the students 
and the theorist style $(\mathrm{r}=0.2 ; \mathrm{p}<0.0001)$; conversely, a statistically significant negative correlation was observed between higher GPA and the activist style $(r=-0.1 ; p=0.04)$. The multivariate linear regression model showed that the theorist style protects against a lower mean of GPA in students $(\beta=-0.2 ; p=0.018)$ after adjusting for sex, age, public high school, and semester enrolled (Table 3). The variable students who have studied in public high school was significant in the model.

Table 3. Simple and multivariate linear regression models for the theorist style in students and grade point average.

\begin{tabular}{ll}
\hline Model & $\beta$, confidence interval, and explanatory variables \\
\hline Simple GPA & $-0,206(-3,61 \text { to }-0,52)^{*}$ \\
Multivariate GPA & $-0,208(-3,81 \text { to }-0,35)^{* * *}+0,07^{* * *}{ }_{\text {PHS }}-0,71_{\text {gender }}-0,07_{\text {age }}-0,008_{\text {SE }}$ \\
\hline GPA $=$ grade point average; \\
PHS = students who have studied in public high school; \\
SE = semester enrolled; \\
$* \mathrm{p}=0.009 ;$ \\
$* * \mathrm{p}=0.01 ;$ \\
$* * * \mathrm{p}=0.02$.
\end{tabular}

The mean and standard deviation of LS (between the three groups) was contrasted (Table 4). Students and professors showed a predilection for the theorist and reflector styles (moderate); nevertheless, the applicant students had a higher predilection for the theorist style $(\mathrm{p}=0.002)$. Also, the pragmatist style showed a larger scale in the applicant students $(<0.001)$.

Table 4. Mean values and rating scale of the learning styles in faculty members.

\begin{tabular}{llllllll}
\hline Learning Style & $\begin{array}{l}\text { Applicants } \\
(\mathrm{n}=34)\end{array}$ & $\begin{array}{l}\text { Rating } \\
\text { scale }\end{array}$ & $\begin{array}{l}\text { Students } \\
(\mathrm{n}=425)\end{array}$ & $\begin{array}{l}\text { Rating } \\
\text { scale }\end{array}$ & $\begin{array}{l}\text { Professors } \\
(\mathrm{n}=121)\end{array}$ & $\begin{array}{l}\text { Rating } \\
\text { scale }\end{array}$ & P value \\
\hline Activist & $25.5 \pm 5$ & $\mathrm{l}$ & $25.4 \pm 4$ & $\mathrm{l}$ & $24.1 \pm 4.4$ & 1 & $\mathrm{NS}$ \\
Reflector & $34.5 \pm 4.6$ & $\mathrm{~m}$ & $32.7 \pm 4.8$ & $\mathrm{~m}$ & $33.2 \pm 4.7$ & $\mathrm{~m}$ & $\mathrm{NS}$ \\
Theorist & $35.3 \pm 4.5$ & $\mathrm{~h}$ & $32.3 \pm 5$ & $\mathrm{~m}$ & $34.7 \pm 4.8$ & $\mathrm{~m}$ & $0.002^{*}$ \\
Pragmatist & $30.4 \pm 4.6$ & $\mathrm{~m}$ & $28.1 \pm 4.7$ & $\mathrm{~m}$ & $27 \pm 4.9$ & $\mathrm{~m}$ & $<0.001^{* *}$ \\
\hline
\end{tabular}

Values are presented as a mean \pm standard deviation;

Rating scale: very high (vh), high (h), moderate (m), low (l) and very low (vl).

$\mathrm{NS}=$ not statistically significant;

*Statistically significant differences between students and applicants;

**Statistically significant differences between applicants and students and between applicants and professors.

Table 5 shows the academics degree of the professors and their LS. Ph.D. and master professors showed a predilection for the theorist and reflector styles (moderate), specialists for the theorist (high), and Doctor of Dental Surgery (DDS) professors for the reflector (high). A statistically significant difference was observed between master and specialist professors in the theorist style $(\mathrm{p}=0.02)$. 
Table 5. Academic degree of the professors and their learning styles

\begin{tabular}{lllllllll}
\hline Learning Style & $\begin{array}{l}\text { Ph.D. } \\
(\mathrm{n}=17)\end{array}$ & $\begin{array}{l}\text { Rating } \\
\text { scale }\end{array}$ & $\begin{array}{l}\text { Master } \\
(\mathrm{n}=27)\end{array}$ & $\begin{array}{l}\text { Rating } \\
\text { scale }\end{array}$ & $\begin{array}{l}\text { Specialists } \\
(\mathrm{n}=70)\end{array}$ & $\begin{array}{l}\text { Rating } \\
\text { scale }\end{array}$ & $\begin{array}{l}\text { DDS } \\
(\mathrm{n}=7)\end{array}$ & $\begin{array}{l}\text { Rating } \\
\text { scale }\end{array}$ \\
\hline Activist & $24 \pm 4.2$ & 1 & $23.7 \pm 3.4$ & 1 & $23.9 \pm 4.7$ & 1 & $25.5 \pm 6.1$ & 1 \\
Reflector & $32.8 \pm 4.8$ & $\mathrm{~m}$ & $32.7 \pm 3.9$ & $\mathrm{~m}$ & $32.6 \pm 4.7$ & $\mathrm{~m}$ & $35.2 \pm 4.4$ & $\mathrm{~h}$ \\
Theorist & $33.9 \pm 6.3$ & $\mathrm{~m}$ & $33 \pm 4.4$ & $\mathrm{~m}$ & $35.5 \pm 4.2^{*}$ & $\mathrm{~h}$ & $34.8 \pm 5.2$ & $\mathrm{~m}$ \\
Pragmatist & $27.1 \pm 7$ & $\mathrm{~m}$ & $26.1 \pm 4.1$ & 1 & $25.7 \pm 4.2$ & 1 & $28.8 \pm 6.3$ & $\mathrm{~m}$ \\
\hline
\end{tabular}

Values are presented as a mean \pm standard deviation.

Rating scale: very high (vh), high (h), moderate (m), low (l) and very low (vl).

* Statistically significant differences between master and clinical specialists.

Table 6 presents the learning styles of Ph.D. professors, depending on the place of academic training (Colombia versus outside of Colombia). Ph.D. professors trained in Colombia showed a preference for the theorist and reflector styles (moderate), while Ph.D. professors trained outside of Colombia presented predilection for the reflector (high) $(\mathrm{p}=0.03)$. Besides, differences were observed in the pragmatist style.

Table 6. Learning styles of Ph.D. professors depending on the place of academic training

\begin{tabular}{lllll}
\hline Learning Style & $\begin{array}{l}\text { Colombia } \\
(\mathrm{n}=8)\end{array}$ & $\begin{array}{l}\text { Rating } \\
\text { scale }\end{array}$ & $\begin{array}{l}\text { Outside Colombia } \\
(\mathrm{n}=9)\end{array}$ & $\begin{array}{l}\text { Rating } \\
\text { scale }\end{array}$ \\
\hline Activist & $23.1 \pm 3.5$ & 1 & $24.8 \pm 4.8$ & 1 \\
Reflector & $30.2 \pm 4.4$ & $\mathrm{~m}$ & $35.1 \pm 4 *$ & $\mathrm{~h}$ \\
Theorist & $33.9 \pm 7$ & $\mathrm{~m}$ & $34 \pm 6.1$ & $\mathrm{~m}$ \\
Pragmatist & $25.2 \pm 4.8$ & 1 & $28.8 \pm 8.4$ & $\mathrm{~m}$ \\
\hline
\end{tabular}

Values are presented as a mean \pm standard deviation.

Rating scale: very high (vh), high (h), moderate (m), low (l) and very low (vl).

* Statistically significant differences.

\section{Discussion}

It has been expressed the LS as the manner to intake, remind and recall knowledge, easing the course of information and abilities. The individuality and career can be an essential feature that may determine the LS, providing to the $50 \%$ of the changeability in learning (Contessa et al., 2005).

In different cultures around the world, it has been described that the background and their peculiarities affect the LS (Chuenjitwongsa et al., 2018). Besides, it has been documented that Hispanic-Latino reported a different learning style preference; their learning styles and environmental contexts involve some particularities: less independent learning, a higher degree of structure, and formal design (Falk-Kessler et al., 2006).

In general, the present research shows that applicants, students, and professors presented preference for the theorist and reflector styles; however, some particularities are discussed below.

Although learning styles and its relationship between students and professors in dental schools has scarcely been studied, a program of medicine presented that professors and students preferred the reflector style. When the identical LS are common, a didactic link is obtained, and then it is possible to improve learning objectives (Adesunloye et al., 2008).

Instead, it was described that faculty members in a medical residency program selected the pragmatist style (Richard et al., 2014). Similarly, in the present study, the pragmatist style was observed in the three groups on a moderate scale; however, the pragmatist style had a higher value in the applicants compared to the other groups. It was reported that the pragmatist style was very successful in problem-based learning strategies in medicine programs (Gurpinar et al. 2011). 
Literature (Madrigal \& Trujillo, 2014), pharmacy (Czepulat et al. 2016), and medicine pupils also adopted the theorist and reflector styles (Márquez et al. 2014). Therefore, individuals with a preference in the theorist style (Table 1) desire to assess difficulties; they are observers, study methodically, and explore the evidence. On the other hand, reflectors are quiet and investigative (Márquez et al., 2014).

The present investigation found that the activist and pragmatist styles were present in a low and moderate scale, respectively, contrasting the results observed in dental programs from other ethnic backgrounds (ALQahtani \& Al-Gahtani, 2014; Hosseini et al., 2015). Nonetheless, reports finished at diverse health institutions displayed varied findings of prevalent LS among faculty and students (Turner et al., 2011).

The present research found a positive statistically significant correlation between a higher GPA of the students and theorist style, and a negative statistically significant correlation between higher GPA and activist style. Besides, the adjusted multivariate linear regression model showed that the theorist style protects against a lower mean of GPA in students. Similarly, an important influence of learning style form on academic achievement was observed in surgery residents (Contessa et al., 2005). Contrariwise, other findings in dental schools did not show these classes of relationships (ALQahtani \& Al-Gahtani, 2014; Hosseini et al., 2015). Numerous features impact achievement; it is presumed that LS only may not anticipate academic success (Richard et al., 2014). Moreover, some researchers specify that social multiplicities could create a distinction in the predilections of LS; they connect them to reasoning and interaction varieties (Chuenjitwongsa et al., 2018; Turner et al., 2011). These opinions might elucidate the tendencies reported in the present research.

When professors know the applicants' and students' preferences in LS, it is more feasible to establish methodologies that allow them to learn more efficiently (Czepula et al., 2016). To generate these strategies, the results of the present research were communicated to the faculty members of the School of Dentistry of the University of Antioquia.

The present study showed a statistically significant correlation between students who have studied in public high schools and lower grade point average, corroborating previous results (Dube \& Mlotshwa, 2018; Coffield et al., 2004).

The present investigation observed that Ph.D. and master professors had a predilection for the theorist and reflector styles, specialists for the theorist, and DDS for the reflector. To our knowledge, no one study has reported learning style preferences between professors with different academic degrees. The addition of more cognitive abilities in association with attitudes to learning has the potential to improve the teaching-learning process. With the comprehension of their potencies and limitations as learners, professors can become more interested to learn and consequently become constant learners (Coffield et al., 2004), which is indispensable for a career in dentistry.

In the present study, Ph.D. professors trained in Colombia showed a preference for the theorist-reflector styles, while Ph.D. professors trained outside Colombia presented predilection for the reflector style. The dissimilarities between learning styles maybe because of cultural variety; as cultures are diverse, it is usual to presume contrast in the styles of learning in some countries (Hong, 2009).

The present study has some limitations. The design of the study avoids chronological causality. The group studied is not representative of the nation; nevertheless, the institution studied is the second major university in the country with a relevant number of candidates from diverse provinces. Besides, these findings provide information that can help to improve the teaching-learning process, knowing the preferred LS of the faculty members. More researches exploring the connection between professors and students concerning LS in dental schools are needed to compare these findings with other contexts.

Concluding, students preferred the theorist and reflector styles; however, the applicant students favored the theorist and pragmatist. Besides, the theorist style protects against a lower mean of GPA in students. Ph.D. and master professors chose the theorist and reflector styles, specialists the theorist, and DDS professors the reflector. The learning styles of the faculty members observed in the present research could be related to particular contexts. These outcomes could institute approaches in the learning-teaching process in dental programs in Latin America.

\section{Acknowledgments}

The Faculty of Dentistry of the Universidad de Antioquia, Medellín, Colombia, funded the present investigation.

\section{Competing Interests Statement}

The authors declare that there are no competing or potential conflicts of interest. 


\section{References}

Adesunloye, B. A., Aladesanmi, O., Henriques-Forsythe, M., \& Ivonye, C. (2008). The preferred learning style among residents and faculty members of an internal medicine residency program. Journal of the National Medical Association, 100, 172-175. https://doi.org/10.1016/S0027-9684(15)31205-0

AL Qahtani, D. A., \& Al-Gahtani, S, M. (2014). Assessing learning styles of Saudi dental students using Kolb's Learning Style Inventory. Journal of Dental Education, 78, 927-933.

Ali, P. A., Gavino, M. I., \& Memon, A. A. (2007). Predictors of academic performance in the first year of basic nursing diploma programme in Sindh, Pakistan. Journal of the Pakistan Medical Association, 57, 202-204.

Alonso, C., Gallego, D., \& Honey, P. (2012). Los estilos de aprendizaje: Procedimientos de diagnóstico y mejora [Learning styles: Diagnostic and improvement procedures] Bilbao: Ediciones Mensajero. Spanish

Baker, J. D., \& Marks, W. E. (1981). Learning style analysis in anesthesia education. Anesthesiology Review, 8, 31-34.

Chuenjitwongsa, S., Bullock, A., \& Oliver, R. G. (2018). Culture and its influences on dental education. European Journal of Dental Education, 22, 57-66. https://doi.org/10.1111/eje.12244

Coffield, F., Moseley, D., Hall, E., \& Ecclestone, K. (2004). Learning styles and pedagogy in post-16 learning: A systematic and critical review. London, England: Learning and Skills Research Centre.

Coloma, C. M., Manrique, L., Revilla, D., \& Tafur, R. (2008). Estudio Descriptivo de los estilos de aprendizaje de docentes universitarios. Journal of Learning Styles, 1, 124-142

Contessa, J., Ciardiello, K. A., \& Perlman, S. (2005). Surgery resident learning styles and academic achievement. Current Surgery, 62, 344-347. https://doi.org/10.1016/j.cursur.2004.09.012

Czepula, A. I., Bottacin, W. E., Hipólito, E. Jr., Baptista, D. R., Pontarolo, R., \& Correr, C. J. (2016). Predominant learning styles among pharmacy students at the Federal University of Paraná, Brazil. Pharmacy Practice (Granada), 14, 650. https://doi.org/10.18549/PharmPract.2016.01.650

Divaris, K., Polychronopoulou, A., Taoufik, K., Katsaros, C., \& Eliades, T. (2012). Stress and burnout in postgraduate dental education. European Journal of Dental Education, 16, 35-42. https://doi.org/10.1111/j.1600-0579.2011.00715.x

Dube, M. B., \& Mlotshwa, P. R. (2018). Factors influencing enrolled nursing students' academic performance at a selected private nursing education institution in KwaZulu-Natal. Curationis, 41, e1-e7. https://doi.org/10.4102/curationis.v41i1.1850

Falk-Kessler, J., Emery, L. J., \& Scoggin, A. E. (2006). Learning styles of university students in a Hispanic-serving institution. Occupational Therapy in Health Care, 19, 83-96. https://doi.org/10.1080/J003v19n04_06

González-Haro, C., Calleja-González, J., \& Escanero, J. F. (2010). Learning styles favoured by professional, amateur, and recreational athletes in different sports. Journal of Sports Sciences, 28, 859-866. https://doi.org/10.1080/02640411003734077

Gurpinar, E., Bati, H., \& Tetik, C. (2011). Learning styles of medical students change in relation to time. Advances in Physiology Education, 35, 307-311. https://doi.org/10.1152/advan.00047.2011

Honey, P., \& Mumford, A. (1986). Using our learning styles. Maidenhead: Peter Honey. U.K.: Berkshire.

Hosseini, S. M., Amery, H., Emadzadeh, A., \& Babazadeh, S. (2015). Dental Students' Educational Achievement in Relation to Their Learning Styles: A Cross- Sectional Study in Iran. Global Journal of Health Science, 7, 152-158. https://doi.org/10.5539/gjhs.v7n5p152

Keefe, J. W. (1988). Profiling and Utilizing Learning Style. Reston, VA NASSP Learning Style Series.

Kolb, D. A. (1984). Experimental learning: experience as the source of learning and development. Englewood Cliffs: Prentice-HallInc.

Madrigal Gil, A. J., \& Trujillo Torres, J. M. (2014). Adaptación del cuestionario Honey-Alonso de estilos de aprendizaje para estudiantes de una institución universitaria de Medellín-Colombia [Adaptation of the Honey-Alonso questionnaire of learning styles for students of a university institution of Medellín-Colombia]. Journal of Learning Styles, 7, 155-181

Márquez, U. C., Fasce, H. E., Pérez, V. C., Ortega, B. J., Parra, P. P., Ortiz, M. L., ... Ibáñez, G. P. (2014). 
Relationship between self-directed learning with learning styles and strategies in medical students. Revista Medica de Chile, 142, 1422-1430. https://doi.org/10.4067/S0034-98872014001100009

Morris, D. O. (2000). Personality types of dental school applicants. European Journal of Dental Education, 4, 100-107. https://doi.org/10.1034/j.1600-0579.2000.040302.x

Pulcini, G. G., Porcarelli, A., Angeletti, M., \& Polzonetti, V. (2018). Alla ricerca di strumenti per l'orientamento universitario: prima traduzione ufficiale del cuestionario adaptado de estilos de aprendizaje. Rivista Interdisciplinari dell'Educazione, 11,174-204

QS World University Ranking. Retrieved April 20, 2019, from https://www.topuniversities.com/latin-american-rankings

Revilla, D. (1999). Los estilos de aprendizaje. Revista Autoeducación, 55, 7-10

Richard, R. D., Deegan, B. F., \& Klena, J. C. (2014). The learning styles of orthopedic residents, faculty, and applicants at an academic program. Journal of Surgery Education, 71, 110-118. https://doi.org/10.1016/j.jsurg.2013.05.011

Rutter, H., Herzberg, J., \& Paice, E. (2002). Stress in doctors and dentists who teach. Medical Education, 36, 543-549. https://doi.org/10.1046/j.1365-2923.2002.01229.x

Turner, D. A., Narayan, A. P., Whicker, S. A., Bookman, J., \& McGann, K. A. (2011). Do pediatric residents prefer interactive learning? Educational challenges in the duty hours' era. Medical Teacher, 33, 494-496. https://doi.org/10.3109/0142159X.2010.542524

\section{Copyrights}

Copyright for this article is retained by the author(s), with first publication rights granted to the journal.

This is an open-access article distributed under the terms and conditions of the Creative Commons Attribution license (http://creativecommons.org/licenses/by/4.0/). 